\title{
UMA ANÁLISE DA REPERCUSSÃO DE DISCURSOS DISCRIMINATÓRIOS NA MÍDIA, SOB A ÓTICA DA DINÂMICA SOCIAL
}

\author{
CLAUTON DE REZENDE ${ }^{1}$ \\ Universidade Federal de São João del-Rei \\ Praça Frei Orlando, 170 - 36307-352 - São João del-Rei - Minas Gerais - Brasil \\ clauton.de.rezende@hotmail.com
}

\begin{abstract}
Resumo. Levando-se em conta a repercussão que discursos discriminatórios têm nos veículos eletrônicos de imprensa, especialmente pelo debate que causa nas redes sociais, este trabalho se propõe a analisar a seletividade presente no conteúdo repercutido pela imprensa eletrônica, com o objetivo de tentar entender os aspectos culturais que determinam a inclusão $e$ exclusão de discursos, a princípio, semelhantes. Para isso, utilizaremos da proposta de análise do discurso como uma dinâmica que promove mudanças sociais e teremos, como objeto de análise, um programa de televisão conhecido como jogo dos pontinhos - que causou debate online, por possivelmente ter dado espaço para discursos discriminatórios.
\end{abstract}

Palavras-chave: jogo dos pontinhos; discurso e mudança social; ateísmo; homofobia.

\begin{abstract}
Considering repercussion of discriminatory speeches on electronic press, especially due to the debate it causes in social networks, this paper proposes to analyze the selection present in the content reflected by the electronic press, with the aim of trying to understand cultural aspects that determine the inclusion and exclusion of speeches that are similar, a priori. For this, we will use the discourse analysis as a dynamic that promotes social change and we will have, as the object of analysis, a television show - known as "jogo dos pontinhos" - that caused online debate, possibly to give way to discriminatory speeches.
\end{abstract}

Keywords: jogo dos pontinhos; discourse and social change; atheism; homophobia.

\section{INTRODUÇÃO}

A programação dominical do canal de televisão SBT é conhecida nacionalmente como Programa Sílvio Santos que, sob o comando de Senor Abravanel (conhecido como Sílvio Santos), que também é o proprietário da emissora, apresenta muitas atrações de variedades. É em um desses programas que está inserido o chamado jogo dos pontinhos.

O jogo dos pontinhos trata-se de uma espécie de bancada onde pessoas famosas, incluindo humoristas e outros apresentadores, dão opiniões baseadas em perguntas feitas

\footnotetext{
${ }^{1}$ Mestrando em Teoria Literária e Critica da Cultura na Universidade Federal de São João Del-Rei.
} 
pelo apresentador Sílvio Santos. As perguntas feitas têm a intenção de provocar situações de humor, a fim de entreter o telespectador.

Em maio de 2016, O jogo dos pontinhos causou polêmica na mídia eletrônica ${ }^{21}$, ao tratar sobre relacionamento homoafetivo. No domingo 08/05/2016, Sílvio Santos fez várias perguntas polêmicas aos seus colegas de bancada: "Você é a favor ou contra a pessoa que não acredita em Deus?"; "você é a favor ou contra o prisioneiro, que está cumprindo pena, ir pra casa passar o Natal ou o Dias das Mães?"; "você é contra ou a favor ter filhos antes do casamento?". 32

Ao responder a uma dessas perguntas, Patrícia Abravanel, que é filha de Sílvio Santos e uma das apresentadoras, emitiu uma opinião que causou polêmica na mídia eletrônica. A apresentadora teria se manifestado de forma preconceituosa contra os homossexuais.

Esse acontecimento nos chamou a atenção para a questão das minorias e como ela tem sido discutida nas mídias. Embora seja compreensível a repercussão negativa a respeito de um ato discriminatório, ao assistirmos ao jogo dos pontinhos, verificamos que Patrícia Abravanel e os outros participantes "discriminaram" outro grupo minoritário (que se sentiu incomodado), no entanto, sem causar a mesma comoção nas mídias. Esse outro grupo são os ateus ${ }^{43}$.

Com base nos fatos acima expostos, este trabalho pretende fazer uma análise da repercussão do jogo dos pontinhos na mídia e refletir sobre os aspectos linguísticos que possam apontar para uma compreensão do tratamento diferenciado que é dado, pela mídia, a grupos igualmente discriminados socialmente.

Faremos, inicialmente, um resumo, com um apanhado de reportagens na mídia, mas, principalmente, composto de pesquisas desenvolvidas por institutos de pesquisa. Esse tópico inicial visa conceber um panorama sobre a visão popular em relação às pessoas que não acreditam em Deus, de forma que possa justificar nossa problematização, relacionada à falta de repercussão sobre a imagem negativa veiculada pelo jogo dos pontinhos a respeito desse grupo, visto que essa representação ocorreu no mesmo episódio em que se repercutiu sobre o grupo LGBT.

Utilizaremos os estudos de Bourdieu (2007), a respeito dos campos sociais, especialmente o "campo religioso", o qual ele aborda em sua obra "A Economia das trocas simbólicas" (BOURDIEU, 2007). Partiremos dessa noção de "campo social como um espaço de luta de classes" para que seja possível entender a relação simbólica da linguagem em contato com a religião, proposta pelo autor, que, por meio de um resumo da história da sociologia, classifica o discurso religioso como uma linguagem. Aprofundaremos a abordagem sobre discurso religioso com base nos estudos de Orlandi

\footnotetext{
2 Trataremos como "mídia eletrônica" a versão online dos jornais impressos, bem como as redes sociais, onde ocorre boa parte dos debates políticos e ideológicos entre cidadãos comuns pela internet.

3 O programa pode ser acessado pela internet, em duas partes, nos links https://www.youtube.com/watch?v=VA2OS dRrmU e https://www.youtube.com/watch?v=TQcJlcMBsfc. Acesso em 19/11/2016.

4 Trataremos a palavra "ateu" no seu sentido etimológico, ou seja, pessoa que nega a existência de Deus (ou deuses). O termo é controverso, pois muitos relacionam "ateísmo" à certeza da inexistência de deus. No entanto, trataremos como "negação do teísmo", ou "pessoas sem fé", ou "descrentes".
} 
(2007) e sua perspectiva sobre política da palavra, incluindo outros de seus estudos sobre essa modalidade de discurso, que considera que, "na ordem do discurso religioso, o sujeito se marca pela submissão, isto propicia múltiplas espécies de manipulação" (ORLANDI, 1987, p. 15). Por fim, nos ancoraremos, também no trabalho de Lemke (1993a), que considera a mudança social como resultante de uma dinâmica que envolve supersistemas e subsistemas, o que significa que estamos "presos" a processos mais complexos do que podemos controlar. Ao mesmo tempo, sua hipótese é de que os supersistemas podem sofrer mudanças devido a demandas do subsistema, mesmo que haja a imprevisibilidade no resultado mutante - relação que se aplica, segundo Lemke (1993a), a aspectos culturais e linguísticos.

\subsection{UM PANORAMA DOS DESCRENTES COMO MINORIA}

Pensamos ser importante tecermos um panorama sobre os descrentes no Brasil. Em determinado momento de nossa pesquisa e em conversas pessoais, notamos uma relutância em classificar ateus/agnósticos como minoria. Tendo em vista que isso tenha acontecido em âmbito de conversas pessoais com alguns estudiosos (de outras temáticas), achamos válido reservarmos um subcapítulo de nossa introdução para este breve panorama estatístico. Isso será feito de maneira breve, apenas pelas razões supracitadas.

A Fundação Perseu Abramo divulgou uma pesquisa ${ }^{54}$, realizada em parceria com a fundação alemã Rosa Luxemburg Stiftung, na qual foram feitas várias perguntas a respeito de grupos sociais minoritários. Uma das perguntas, a título de exemplo, era "vou falar de alguns tipos de pessoas e gostaria que o/a sr/a. me dissesse o que o/a sr/a. sente normalmente quando vê ou encontra desconhecidos do tipo deles.". A pesquisa tinha, como objetivo, fazer um levantamento sobre a aceitação dos povos indígenas pelos brasileiros. No entanto, para nós, ela acabou se tornando importante para mensurar o preconceito que atinge outros grupos minoritários. No caso dos ateus, a pesquisa tornouse importante por ter mostrado esse grupo sempre no topo das listas dos grupos que constam nas perguntas, como os mais rejeitados - sempre em primeiro ou segundo lugar. Alguns grupos citados na pesquisa eram: índios, gente que não acredita em Deus, usuários de drogas, ciganos, garotos de programa, travestis, ex-presidiários, gente muito rica, gente muito religiosa, prostitutas, gays e lésbicas, judeus, estrangeiros, entre outros. As opções de resposta a essa pergunta que usamos como exemplo eram as seguintes: repulsa/ódio, antipatia, indiferença, satisfação/alegria, dó/pena, outras. A tabela com os resultados obtidos pode ser vista no Anexo I. Ela mostra que, dentre esses grupos, os ateus são os "campeões" do sentimento de repulsa/ódio (17\%), ficando, também em segundo lugar $(25 \%)$ no quesito antipatia, atrás apenas de usuários de drogas $(27 \%)$. Interessante observar que gays e lésbicas sofrem menos que os ateus do sentimento de repulsa e ódio. Nos Anexos II e III, a pergunta foi "Desses grupos todos, qual é o que você menos gosta de encontrar?". No Anexo IV ${ }^{65}$, a pergunta foi "Em qual dos grupos listados você nunca votaria numa eleição?", pergunta que revelou os negros (96\%), as mulheres (92\%) e os

\footnotetext{
5 Os detalhes sobre a pesquisa podem ser acessados pelo endereço eletrônico da Fundação: https://fpabramo.org.br/publicacoes/publicacao/indigenas-no-brasil-demandas-dos-povos-e-percepcoesda-opiniao-publica/.

${ }^{6}$ Essa é outra pesquisa da FPA com resultados desfavoráveis aos ateus descobertos "por acaso". Detalhes podem ser acessados em: https://fpabramo.org.br/publicacoes/publicacao/pesquisa-mulheres-brasileiras-egenero-nos-espacos-publico-e-privado-2010/. Acesso em 19/11/2016.
} 
homossexuais $(63 \%)$ com maior chance de serem eleitos que ateus $(20 \%)$. Resultado parecido revelou uma pesquisa do CNT/Sensus ${ }^{76}$, dessa vez, para o cargo de presidente do Brasil. Os resultados foram: $84 \%$ dos brasileiros votariam em um negro para presidente da República, 57\% em uma mulher, 32\% aceitariam um homossexual, mas apenas $13 \%$ votariam em um candidato ateu (as pesquisas estão mais detalhadas nos respectivos Anexos, com o intuito de não nos estendermos muito textualmente).

Em matéria publicada pela BBC Brasil ${ }^{87}$, em 06/11/2016, sugere-se que, “até hoje, há quem diga que Fernando Henrique Cardoso só não ganhou de Jânio Quadros, na disputa pela prefeitura de São Paulo, em 1985, porque titubeou diante de uma pergunta do jornalista Boris Casoy, no último debate na TV, sobre sua crença em Deus." Na mesma matéria, Geraldo José de Paiva, coordenador do Laboratório de Psicologia Social da Religião, do Instituto de Psicologia da USP compara: "mexer com Deus é como mexer com a mãe".

É importante ressaltar, antes de prosseguirmos, a dificuldade em se encontrar esse tipo de dados. Muitas vezes, eles só estão disponíveis em blogs, na internet, que nos levam para as fontes oficiais. Normalmente são blogs ou comunidades formadas em redes sociais com a finalidade de tratar do tema "ateísmo". Até mesmo nas pesquisas encontradas, como no caso das pesquisas da Fundação Perseu Abramo, a relevância desse tipo de preconceito depende da interpretação de quem tem contato com a pesquisa. Isso porque a intenção da pesquisa era outra - a de traçar um perfil sobre a imagem que os brasileiros têm sobre os indígenas. Ou seja, apenas olhares atentos à questão religiosa conseguem ser despertados pela manutenção dos ateus sempre no topo da lista de grupos "odiados" socialmente, já que a pesquisa, por si só, está interessada na questão indígena.

\subsection{REVISÃO DE LITERATURA}

Bourdieu (2007) trabalha com uma noção de "bens simbólicos", que ele chama de "capital cultural". Ao longo de sua obra, Bourdieu (2007) alerta para a "ilusão" de que o ensino público, por ser acessível a todas as camadas sociais, esteja, de fato, sendo igualitário. Para ele, mesmo tendo acesso ao mesmo conteúdo dentro de uma sala de aula, a apreensão desse conteúdo não acontece de forma igualitária, pois alguns alunos vêm de famílias com um maior "capital cultural" que outros. O sociólogo Sérgio Miceli, que organizou a coleção de textos presentes nessa obra de Bourdieu (2007), escreve na introdução:

o trajeto de Bourdieu visa aliar o conhecimento da organização interna do campo simbólico - cuja eficácia reside justamente na possibilidade de ordenar o mundo natural e social através de discursos, mensagens e representações, que não passam de alegorias que simulam a estrutura real de relações sociais - a uma percepção de sua função ideológica e política e legitimar uma ordem arbitrária em que se funda o sistema de

\footnotetext{
${ }^{7}$ A pesquisa do CNT/Sensus foi encomendada pela Revista Veja. Os resultados estão na edição com data de 26/12/2007 e também podem ser conferidos no acervo online da revista. O endereço para acesso direto, anteriormente disponível no endereço eletrônico https://veja.abril.com.br/261207/p 070.shtml encontra-se, atualmente, restrito, disponível apenas para assinantes. Os resultados da pesquisa foram publicados dentro da matéria "Como a fé resiste à descrença", escrita pelo então colunista da revista André Petry.

${ }^{8}$ Disponível em: http://www.bbc.com/portuguese/brasil-37640191. Acesso em 19/11/2016.
} 
dominação vigente. (BOURDIEU, 2007, p. XIV)

Bourdieu (2007) argumenta que aquilo que conhecemos como "boa cultura" (no sentido de bagagem de conhecimento e erudição) é instituído de forma arbitrária, pois quem decide a importância ou não de um determinado tipo de conhecimento, ou de uma forma de arte, em detrimento de outro, são grupos de pessoas que têm acesso a essa "bagagem", que é constituída através de um histórico familiar que permite a esse grupo o acesso a tais obras. Bourdieu (2007) cita um museu, para exemplificar, sugerindo que o museu demanda, do visitante, "a posse de um código cultural mais ou menos complexo, e por conseguinte mais ou menos raro, e necessário ao deciframento das obras expostas". (BOURDIEU, 2007. p. 306). Ou seja, existe uma "competência cultural e linguística" (BOURDIEU, 2007. p. 306) exigida como instrumento para aquisição do "capital cultural".

Dessa forma, cria-se um caráter cíclico que permite apenas aos grupos já detentores desse capital, sua aquisição. A competência linguística e cultural e a relação de intimidade com a cultura e com a linguagem são "instrumentos que somente a educação familiar pode produzir quando transmite a cultura dominante" (BOURDIEU, 2007. p. 307) e, para o sociólogo, esses instrumentos são negados de forma implícita pelo sistema educacional. Nessa espécie de "mercado simbólico", Bourdieu (2007) sugere que existe uma constante tensão e disputa entre os detentores do capital relativo ao campo social e aqueles com menor capital, o que acaba por promover uma dinâmica dentro do campo, ambos os lados, no entanto, ainda reproduzindo as "regras do jogo", incluindose, em alguns casos, como no discurso religioso, a "violência simbólica" (ORLANDI, 1987, p. 8).

Bourdieu (2007) aborda a religião recuperando teorias de Émile Durkheim, Max Weber e Karl Marx, relacionando-as de forma a tentar "reunir os meios de integrar em um sistema coerente as contribuições das diferentes teorias parciais e mutuamente exclusivas [...] é preciso situar-se no lugar geométrico das diferentes perspectivas." (BOURDIEU, 2007. p. 27-28).

Bourdieu (2007) entende que há problemas epistemológicos que impossibilitam a convergência entre essas teorias, e faz uma análise exaustiva acerca do pensamento dos três autores a respeito da religião.

[...] Em plano mais profundo, [Weber] chega a construir o sistema de crenças e práticas religiosas como a expressão mais ou menos transfigurada das estratégias dos diferentes grupos de especialistas em competição pelo monopólio da gestão dos bens de salvação e das diferentes classes interessadas por seus serviços. Neste ponto, Weber está de acordo com Marx ao afirmar que a religião cumpre uma função de conservação da ordem social contribuindo, nos termos de sua própria linguagem, para a "legitimação" do poder dos "dominantes" e para a "domesticação dos dominados. (BOURDIEU, 2007. p. 32)

Bourdieu (2007), após minuciosa análise, define a religião como parte integrante de um sistema simbólico que constrói a percepção sobre o mundo e tem poder político sendo, portanto, importante para a sociologia por construir um sistema de pensamento. 
Se levarmos a sério, ao mesmo tempo, a hipótese de Durkheim da gênese social dos esquemas de pensamento, de percepção, de apreciação e de ação, e o fato da divisão em classes, somos necessariamente conduzidos à hipótese de que existe uma correspondência entre estruturas sociais (em termos mais precisos, as estruturas do poder) e as estruturas mentais, correspondência que se estabelece por intermédio da estrutura dos sistemas simbólicos, língua, religião, arte etc. Em outras palavras, a religião contribui para a imposição (dissimulada) dos princípios de estruturação da percepção e do pensamento do mundo e, em particular, do mundo social, na medida em que impõe um sistema de práticas e de representações cuja estrutura objetivamente fundada em um princípio de divisão política apresentase como a estrutura natural-sobrenatural do cosmos. (BOURDIEU, 2007. p. 33-34)

Pela "monopolização da gestão dos bens de salvação por um corpo de especialistas religiosos" (BOURDIEU, 2007, p. 39), que obtêm reconhecimento social enquanto detentores desses bens, graças à vinculação desses a uma materialidade simbólica, corroborada pela Igreja enquanto um aparelho ideológico do Estado (ALTHUSSER, 1985), constitui-se um campo religioso por meio da negação, aos leigos, do capital religioso (enquanto trabalho simbólico acumulado), sendo, os próprios leigos, contribuintes da legitimidade daquilo que lhes é negado, pelo simples fato de que desconhecem sua própria condição. Os leigos contribuem, com seu silenciamento (ORLANDI, 2007), para sua própria subjugação em relação a esse discurso que ajudam a manter, pois o poder institucional da religião só é efetivado graças a essa dinâmica entre as hierarquias do campo religioso. Como propõe Bourdieu (2007) e Orlandi (2007), há resistências que surgem dessa dinâmica, porém, elas são reguladas, ao longo do tempo, por vias e regimentos diversos, inerentes à própria dinâmica social (LEMKE, 1993a).

Um dos problemas centrais para Lemke (1993a) reside no nosso tempo de vida algumas décadas - em comparação aos séculos de existência dos sistemas que pretendemos moldar. Embora estejamos agindo sobre os sistemas nos quais vivemos, algumas mudanças só podem ser percebidas a prazos longos o suficiente para que tenhamos a impressão que tais mudanças nem estejam acontecendo. Outro fator é nossa posição espacial. "Somos membros de determinada cultura e sociedade, e não outras; falamos algumas línguas, dialetos, registros e discursos, mas não outros" (LEMKE, 1993a, p. 1; tradução nossa).

Nossa ancoragem no trabalho de Lemke (1993a) justifica-se pelo conceito de Dinâmica Social. O autor formula a tese de que vivemos dentro de um sistema complexo formado por supersistemas e subsistemas interdependentes, portanto, moldando um ao outro, provocando transformações a nível linguístico, cultural e natural (que envolve todo o ecossistema).

De uma forma sintética, Lemke (1993a, p.15, tradução nossa) lista três argumentos básicos que explicam sua perspectiva:

1- Sistemas socioculturais são essencialmente sistemas de práticas sociais ligadas histórica e culturalmente a formações semióticas específicas, nas quais constroem significados;

2- Essas práticas são, ao mesmo tempo, processos materiais num complexo, hierarquicamente organizado, desenvolvendo e evoluindo o sistema ecossocial; 
3- As relações dialéticas entre as dimensões, semiótica e materialmente, baseadas nessas práticas / processos são a base para uma dinâmica ecossocial geral.

Lemke (1993a) nos coloca como produtores e receptores de um diálogo semiótico que gera processos evolutivos na linguagem e na cultura, incluindo-nos numa dinâmica dialética que molda-nos a nível individual, social, cultural e natural. Ou seja, as mudanças que fazemos no ambiente também moldam nossos costumes, a níveis difíceis de mensurar - motivo pelo qual ele sugere a evolução cultural oriunda dessa dinâmica como se fosse darwiniana, onde a noção de "controle" é problemática.

A dinâmica cultural da Linguagem não pode ser independente do uso da linguagem, mas se origina diretamente desse uso. A dinâmica cultural da Linguagem-como-sistema, os processos de mudança de Linguagem, representam os efeitos dos recursos semânticos de uma linguagem, de um modo geral, dos novos usos que são feitos dela, registro por registro, função por função, situação por situação. Esse colocar-em-uso é sempre colocar em uso um fazer material de um sistema ecossocial. (LEMKE, 1993a, p. 16; tradução nossa)

Esse "impulso" linguístico é comparado à segunda lei da termodinâmica, a entropia, quando um sistema aberto se reorganiza após sofrer interferência, provocando uma nova ordem na desordem.

O organismo não é um sistema estático fechado ao mundo exterior e contendo sempre os componentes idênticos; é um sistema aberto num estado (quase) estacionário [....] onde materiais ingressam continuamente vindos do meio ambiente exterior, e neste são deixados materiais provenientes do organismo. Diferentemente dos sistemas fechados, que se estabelecem num estado de equilíbrio térmico, os sistemas abertos se mantêm afastados do equilíbrio, nesse "estado estacionário" caracterizado por fluxo e mudança contínuos. (CAPRA 1996, p. 55)

Lemke (1993a) atenta-nos para o que se chama de "emergência". Essa ocorrência se dá quando uma estrutura dissipativa (estruturas com padrões de estabilidade longe do equilíbrio) atinge um ponto crítico de aumento de entropia, mudando para um estado novo de organização. Esse ponto crítico é chamado de "ponto de bifurcação" (Anexo V). A transposição desse conceito para a cultura e a linguagem ajuda-nos a entender por que os processos de mudança cultural acontecem de forma lenta e imprevisível, mesmo com interferências que busquem equilibrá-lo.

Por fim, como já mencionamos, nossa análise também buscará apoio nos conceitos propostos por Orlandi (2007), sobre o que ela chama de política da palavra, que diz respeito a questões de silenciamento e censura que podem ser depreendidos da observação de determinadas formações discursivas, incluindo, aí, aquelas que dizem respeito ao discurso religioso.

Estudando o discurso religioso, tive de passar necessariamente pela questão do silêncio. E para não estacionar no tão conhecido silêncio místico, fiz um esforço de reflexão para pensar as outras formas de silêncio, eu diria mesmo, os outros silêncios. [...] A primeira coisa que 
percebi é que [...] eu havia mal-definido o discurso religioso como "aquele em que fala a voz de Deus" (Orlandi, 1983). Esta definição pode ser interessante para o teólogo mas não o é para o analista do discurso. Dessa perspectiva, a do analista do discurso, o que se pode dizer é que [...], na ordem do discurso religioso, Deus é o lugar da onipotência do silêncio. E o homem precisa desse lugar, desse silêncio, para colocar uma sua fala específica: a de sua espiritualidade. [...] No discurso religioso, não é apenas o mesmo sempre-homem falando; o que importa é que a religião institui um outro lugar e assim dá um estatuto (e, logo, um sentido) diferente a essa fala. Diferença à qual o homem não é indiferente. A partir dessas reflexões, e conduzida pela minha convivência com a discussão sobre o político na linguagem, interessei-me por outra característica desse mesmo tema: a política do silêncio. Isto é, o silenciamento. [...] Em face dessa sua dimensão política, o silêncio pode ser considerado tanto como parte da retórica da dominação (a da opressão) como de sua contrapartida, a retórica do oprimido (a da resistência) (ORLANDI, 2007, p.27-28).

\section{ASPECTOS METODOLÓGICOS}

Tendo em vista que a $\mathrm{AD}$ não pressupõe dados estatísticos como soberanos, devemos levar em consideração as condições de produção, efeitos de sentido, entre outras variáveis presentes nos discursos, aqui materializados nas falas dos participantes do referido jogo dos pontinhos. Também é importante marcar nosso caminho metodológico como situado nas propostas de Pêcheux (2011) e outros teóricos que expandiram a sua concepção de estudos da linguagem, principalmente nos trabalhos de Orlandi (2009), que define o método de pesquisa da $\mathrm{AD}$ como não pronto/acabado:

[...] a construção do corpus e a análise estão intimamente ligados: decidir o que faz parte do corpus já é decidir acerca de propriedades discursivas. Atualmente, considera-se que a melhor maneira de atender à questão da constituição do corpus é construir montagens discursivas que obedeçam critérios que decorrem de princípios teóricos da análise de discurso, face aos objetivos de análise, e que permitam chegar à sua compreensão. (ORLANDI, 1999, p. 63)

Tendo, então, como objeto de investigação as transcrições de opiniões proferidas por atores de um programa de TV a respeito de vários grupos minoritários e percebendo uma alternância entre tolerância e intolerância nessas falas, nossa pesquisa pretende compreender os efeitos de sentido que podem ser depreendidos da materialização dessas opiniões, a nosso ver, "incoerentes", no que diz respeito a haver, nelas, uma alternância entre um discurso de respeito a um grupo minoritário específico, enquanto se observa que o mesmo respeito não acontece em relação a outro grupo, também minoritário (e estatisticamente com maior rejeição popular).

[...] a proposta é a da construção de um dispositivo da interpretação. Esse dispositivo tem como característica colocar o dito em relação ao não dito, o que o sujeito diz em um lugar com o que é dito em outro lugar, o que é dito de um modo com o que é dito de outro, procurando ouvir, naquilo que o sujeito diz, aquilo que ele não diz mas que constitui igualmente os sentidos de suas palavras. (ORLANDI, 1999, p. 59) 
Optamos pela inserção de dados estatísticos acerca do preconceito contra ateus não como forma de mensurar a existência desse tipo de aversão a essa minoria popular, mas para que pudéssemos usá-los como suporte para a compreensão do objeto de investigação - o que se mostrou necessário para a análise, conforme desenvolveremos mais à frente. Os links para o programa completo estão citados neste trabalho, no capítulo de introdução, bem como alguns dados estatísticos estão nos anexos.

Para fazer nossa análise, lançamos mão desse caráter "qualitativointerpretativista" e levamos em conta o programa jogo dos pontinhos como um espaço de regras mais ou menos lineares, embora portadora de uma tensão comum aos campos sociais, devido a valores em disputa dentro dos campos, conforme proposto por Bourdieu (2007) e fizemos uma análise de modo a intercalar o recorte do programa, usado como corpus, com uma "mediação teórica permanente, em todos os passos da análise, trabalhando a intermitência entre descrição e interpretação que constituem, ambas, o processo de compreensão do analista" (ORLANDI, 1999, p. 62).

Ainda como método de análise "qualitativo-interpretativista", também pensamos ser importante lançar mão da Dinâmica Social, proposta por Lemke (1993a), pois ela oferece-nos o benefício de considerar, como importante aspecto de análise, o nosso próprio tempo de vida em comparação com o tempo que se leva para que determinadas mudanças sociais sejam feitas, ou mesmo, assimiladas, por nós, enquanto analistas e enquanto indivíduos. Para Lemke (1993a), é possível mudar o mundo e as pessoas com interferências que objetivam mudanças, porém, as consequências de nossas interferências podem conter um certo grau de imprevisibilidade.

\section{ANÁLISE}

\subsection{REPERCUSSÃO NA MÍDIA}

O Jornal Estadão ${ }^{98}$, no dia 09/05/2016, publicou, em seu site, uma reportagem ${ }^{109}$ sobre o jogo dos pontinhos. No interior do texto, a jornalista Cristina Padiglione chama a atenção para aspectos linguísticos contidos na fala de Patrícia Abravanel. Ao citar a fala da apresentadora, dizendo "não sou contra o homossexualismo, mas sou contra falar que é normal", a jornalista atenta o leitor para o erro no sufixo "ismo" usado pela apresentadora, porque "pode denotar doença mental ou psicológica e foi descartado, cientificamente, em 1973, sendo considerado algo da natureza sexual do ser humano", alegando que "o correto é "homossexualidade". A mesma problematização foi feita pelo site "Catraca Livre", pertencente ao jornalista Gilberto Dimenstein. O "Catraca Livre" já havia feito uma publicação ${ }^{110}$ anterior, no dia 09/05/2016, atualizada ainda no dia 09/05/2016, repercutindo o fato ocorrido no programa, no dia anterior, colocando, no primeiro parágrafo da matéria, a frase "Na noite deste domingo, dia 8, o Programa do Sílvio Santos, no SBT, foi palco de um show de horrores contra a população LGBT.”. Nenhuma menção foi feita sobre as outras formas de preconceito veiculadas. Segundo o

\footnotetext{
${ }^{9}$ Disponível em: http://www.estadao.com.br/. Acesso em 19/11/2016.

10 Disponível em: http://cultura.estadao.com.br/blogs/cristina-padiglione/acusada-de-homofobia-patriciaabravanel-se-desculpa-2/. Acesso em 19/11/2016.

11 Disponível em: https://catracalivre.com.br/geral/cidadania/indicacao/sou-contra-falar-que-ohomossexualismo-e-normal-diz-filha-de-silvio-santos/. Acesso em 19/11/2016.
} 
site, o "show de horrores" atingiu apenas a comunidade LGBT. Na sequência, a Redação do "Catraca Livre" fez uma lista de quatro "dicas" de como as pessoas devem lidar com o grupo LGBT.

No dia 09/05/2016, com atualização no dia 10/05/2016, o site voltou a repercutir o caso ${ }^{1211}$, quando divulgou uma hashtag (\#AnormalÉTeuPreconceito) - sinal comum nas redes sociais para chamar a atenção para um debate que está em alta - argumentando que tal hashtag estava entre as mais usadas na internet - o que evidencia a adesão da população à causa LGBT. Ainda nessa publicação, o site comparou a fala da filha de Sílvio Santos com uma publicação de um neto do mesmo apresentador, Tiago Abravanel, em um aplicativo de celular, em que o neto (que é ator da "Rede Globo") discordava do posicionamento da filha de Sílvio Santos. Na sequência, o site "Catraca Livre" inseriu, dentro da matéria, um vídeo da também atriz Luana Piovani com a seguinte transcrição de sua fala no vídeo:

discordo em gênero, número e grau da Patrícia Abravanel. Acho que toda forma de amor tem que ser abençoada e aplaudida, porque o que falta no mundo é amor", disse ela no vídeo. "Se a gente tivesse mais pessoas generosas, com compaixão, ao redor do mundo, a gente não estaria vivendo tanta crueldade e violência. Acho uma coisa lamentável uma comunicadora privilegiada como a Patrícia dizer uma ignorância dessa em rede nacional. (Catraca Livre)

Finalizando a reportagem, o site incorporou, na matéria, imagens tiradas das redes sociais, de usuários "não-famosos" reagindo negativamente à opinião de Patrícia Abravanel e, como supracitado, aderindo à hashtag.

Com a matéria "Patricia Abravanel se desculpa no Instagram após críticas por comentários homofóbicos", no dia 09/05/2016 (com atualização no dia 13/05/2016), o "Catraca Livre" foi mais enfático em defesa do grupo LGBT. Novamente, a atenção foi voltada apenas a um dos grupos ofendidos pelo jogo dos pontinhos.

Quando alguém com tanto poder e visibilidade dá sua opinião, é claro que as pessoas escutam. É claro que as pessoas dão valor à fala. É é por isso, Patricia, que devemos ter cuidado com o que falamos. Você tem todo o direito de manifestar suas opiniões, mas até um ponto em que a sua opinião não machuque ninguém.

O Catraca Livre acredita no amor em todas as suas formas, e também acredita que a comunidade LGBT não precisa mais de opinião desfavorável. Concordem ou não concordem, o ódio contra os LGBT não vai mudar em nada o que eles de fato são. Nunca mudou, por que mudaria agora? Os LGBT não precisam do aval de ninguém para serem o que são. E é preciso que isso fique muito claro. (Catraca Livre)

Tendo feita a devida contextualização do ocorrido, na sequência, passaremos à análise, com base nos pressupostos teóricos que nos propusemos.

12 Disponível em: https://catracalivre.com.br/geral/cidadania/indicacao/internautas-rebatem-declaracoesde-patricia-abravanel-com-hashtag-anormaleteupreconceito/. Acesso em 19/11/2016. 


\subsection{DIÁLOGOS EM DISCUSSÃO}

Durante o jogo dos pontinhos, houve uma unanimidade, entre os participantes, em ser "contra quem não acredita em Deus". Para Patrícia Abravanel:"(1) [...] a gente fica muito miserável quando não acredita em Deus. Fica só pensando em dinheiro, nas coisas mais materiais. Então, acreditar em Deus eleva a gente espiritualmente. Deixa a gente mais alegre com as coisas que a gente tem; mais contente." [grifo nosso]. Na sequência, Hellen, outra participante, relaciona Deus como necessário para que haja "paz e amor", além de ser incisiva, conforme grifamos em (2), contrastando com os argumentos "tolerantes" que usou em respeito aos LGBT (3):

(2) Hellen: Contra, claro! Contra, Sílvio. Tem que ter em quem acreditar. Ele é nosso Deus! É nosso todo-poderoso! É a coisa que nos traz paz e amor todo dia.

(3) Hellen: A minha opção é pelo sexo oposto, mas eu sou a favor, né, já que é a opção de cada um. Eu gosto de homem, mas eu sou a favor de duas mulheres. [grifo nosso]

Todos os participantes se mostraram muito à vontade ao ser "contra quem não acredita em Deus", ao contrário do desconforto causado pela pergunta sobre duas mulheres homossexuais que, por vezes, eles apoiavam, mesmo que com "ressalvas".

O trecho abaixo foi muito representativo para nossa análise, pois ele é passível de vários tipos de "julgamentos", com base nas expressões usadas pelos participantes (grifamos alguns, como exemplos). A participante Lívia começa ponderando o amor entre duas mulheres, desde que as mulheres sejam "mulheres fisicamente". No entanto, colocase como "a favor" e diz achar "bonito", porque "é amor". Depois, diz pensar que as pessoas são livres, citando, na esfera desse direito à liberdade, a opção sexual e a religião. Ao ser peguntada mais duas vezes, pelo apresentador, se era a favor ou contra "duas mulheres que se amam", ela enfatiza com as palavras "totalmente" e "exatamente", respectivamente:

(4) Lívia: [....] É muito amor, poli amor, é amor pra todo lado! Melhor assim do que ódio. Mas assim, eu acho bonito quando duas mulheres se amam como duas mulheres, entende? Duas mulheres fisicamente; aparentemente como mulheres. Acho muito bonito. É amor! É amor! Sílvio Santos: você é contra ou a favor de duas mulheres que se amam como se fossem marido e mulher?

Lívia: a favor. Totalmente a favor!

Sílvio Santos: Por quê?

Lívia: Porque o mundo é uma coisa livre. A gente vem pra essa Terra, cortou o cordão umbilical, a gente fica livre pro mundo. Cada um escolhe o que quer: opção sexual, religião, o que vai fazer da vida. Cada um com seus problemas. As pessoas têm que respeitar essas escolhas.

Sílvio Santos: Ok. Então você é a favor?

Lívia: Totalmente a favor!

Sílvio Santos: De duas mulheres se amarem como um casal?

Lívia: Exatamente. [grifo nosso] 
Apesar disso, quando perguntada sobre as pessoas que não têm fé, a postura respeitosa (ainda que relutante) se torna, assim como a Hellen (2), incisiva e seguramente contra, conforme destacamos, abaixo, em "tem que ter", "tem que acreditar". Além disso, de novo, a associação entre fé e virtude aparecem, como em "ser humano melhor" e a falta de fé relacionada ao materialismo (no sentido mais popular da palavra - ambição financeira), como em "só ganhar dinheiro":

(5) Lívia: Se Deus é fiel, sangue de Jesus tem poder, São Jorge é guerreiro, eu sou contra quem não acredita em nada. Eu acho que você tem que acreditar em alguma coisa! Tem que ter fé, para se tornar um ser humano melhor e tentar evoluir a cada dia, senão, qual seria o motivo da nossa estada na Terra. Só ganhar dinheiro? Fazer farra? [grifo nosso].

A participante Lívia se contradiz quando, no recorte 4 que fizemos acima, inclui a liberdade religiosa em "Cada um escolhe o que quer: opção sexual, religião" e, na sequência, no recorte 5 , diz "eu sou contra quem não acredita em nada". Possivelmente, para ela, posicionar-se como ateu não é um posicionamento de caráter religioso. No entanto, sabemos que a descrença se insere numa formação discursiva de caráter religioso.

Os ateus acabaram sendo posicionados como os "outros" do discurso de tolerância; aqueles que não devem ter voz para que se mantenha uma unidade nos discursos de tolerância. Não havia nenhum ateu representado no programa. E a representação, portanto, foi feita a partir de um lugar de quem tem fé. Todos os participantes, no programa tem fé. Embora os ateus tenham sido os "alvos" da pergunta feita pelo apresentador, sustentou-se o silenciamento dessa minoria, ainda que em um contexto de "defesa de minorias" (nos casos em que os participantes defenderam o relacionamento entre duas mulheres). É importante ressaltar que, mesmo nas opiniões que se mostraram tolerantes aos LGBT, houve ressalvas. Isso parece demonstrar que a repercussão desse preconceito, nas mídias, tem gerado algum resultado - o que aponta para as questões dinâmicas propostas por Bourdieu (2007), quando considera a tensão gerada por disputas de posição inerente aos campos sociais. No entanto, posicionar-se como descrente também é se posicionar em relação à temática da religião. Logo, o discurso de tolerância deveria ser estendido, logicamente, a esse grupo - o que não aconteceu. "Aí entra toda a questão do "tomar" a palavra, "tirar" a palavra, obrigar a dizer, fazer calar, silenciar etc.”(ORLANDI, 2007, p.27-28), ou seja, as opiniões emitidas deixam de fazer parte de um lugar de "tolerância" para passarem a fazer parte de uma voz do discurso religioso que desconsidera os ateus como inseridos nessa formação discursiva. A voz do discurso religioso é latente nas vozes dos apresentadores que "calam" os ateus. Nesse momento, é a voz de Deus que fala, legitimada pelo discurso religioso, que carrega uma autoridade de dimensão histórica na sociedade, especialmente a brasileira. Mas é uma voz específica (e de censura) dentro do discurso religioso, que evidencia uma parte da população brasileira que ainda vê os ateus como não autorizados a falar de dentro desse discurso.

Quando o site "Catraca Livre" repercute, várias vezes, a fala de Patrícia Abravanel e reforça que "a comunidade LGBT não precisa mais de opinião desfavorável" e que "Os LGBT não precisam do aval de ninguém para serem o que são. E é preciso que isso fique muito claro.", o que fica claro, na nossa proposta crítica, é o silêncio dedicado, pelo site, à outra minoria social atacada pelo jogo dos pontinhos. A importância, que 
pensamos poder chamar de "agravante", é o fato de que o referido site explora muito a militância em relação às minorias, inclusive no que diz respeito a posicionamentos religiosos minoritários. Mas qual seria o motivo da não repercussão sobre a minoria ateia? Seria uma questão comercial? Ou seria, a outra questão - a defesa dos LGBT -, comercial? Acreditamos que essas perguntas também sejam pertinentes, num contexto social em que as empresas têm se esforçado para alcançar o público LGBT. Independente da falta de evidências a respeito do mercado financeiro, apostamos que o "mercado simbólico" (BOURDIEU, 2007) tem influência sobre a exploração da mídia acerca de algumas minorias, enquanto ignora outras. Na própria postagem do "Catraca Livre", há um espaço reservado, dentro da reportagem, à comoção pública, representada ali pelas opiniões da audiência sobre a opinião de Patrícia Abravanel. E sabemos (e pontuamos os dados estatísticos) que, na conjuntura atual, defender ateus não produz o mesmo "valor simbólico" que defender os LGBT.

Da mesma forma, quando o Censo do IBGE não se importa em mensurar a quantidade de descrentes, colocando-os junto aos "crentes sem religião", apaga-se a voz tanto dos ateus quanto dos crentes sem religião. Se levarmos em conta que o Censo visa catalogar as nuances mais diversas possíveis sobre a população, omitir a diferença que há entre um grupo crente e os descrentes é uma falha significativa.

Ainda sobre a questão do silenciamento, a não-repercussão do preconceito contra ateus pelos veículos de mídia que repercutiram o preconceito contra o grupo LGBT demonstra um apagamento daquele grupo enquanto minoria. Mais do que isso, o repúdio aos ateus foi unânime no programa de TV, ao contrário dos outros grupos. Nem mesmo a questão quantitativa foi suficiente para chamar a atenção dos veículos a respeito da "outra" discriminação. Esse aspecto, por si só, poderia ser desenvolvido em uma análise acerca do funcionamento midiático e questões sobre a dinâmica que ocorre entre oferta e demanda de conteúdo, bem como aspectos sobre marketing pessoal dos artistas - o que, obviamente, não pode ser feito neste trabalho. Mas consideremos a ideia do mercado simbólico (BOURDIEU, 2007).

Para Bourdieu (2007), a tensão gerada, por posições em disputa em um campo social, pode ocasionar em mudanças nesse campo. Numa sociedade que cobra, nas redes sociais, um posicionamento a favor de um grupo minoritário específico, é normal que essa sociedade seja modificada nesse sentido específico. Por outro lado, para outro grupo, se não há ação, não há mudança. Onde há silenciamento (ORLANDI, 2007) não há mudança. É evidente (e comprovado, acreditamos, por nossa análise) que não é, hoje, confortável que alguém se posicione publicamente contra o grupo LGBT. E isso não quer dizer que não exista o preconceito. O que isso demonstra é que há um "valor", inserido em um "mercado simbólico", que condena o preconceito contra os LGBT. Esse mesmo mercado simbólico, no entanto, ainda considera normais outros tipos de preconceito contra os ateus, por exemplo.

A "dinâmica social" (LEMKE,1993a) nos oferece uma alternativa de interpretação para a incoerência em ser abertamente "contra quem não acredita em Deus", mas, ao mesmo tempo, "travestir" de tolerância o preconceito contra os LGBT - para a incoerência que problematizamos neste trabalho.

É por meio [da linguagem] que nós construímos as relações de sentido que amarra as práticas sociais de cada formação semiótica. Por meio 
dela que nos fazemos entender e ser entendidos. O que fazemos com a Linguagem (e com todo sistema de recursos semióticos) são relações muito fortes entre processos materiais pelos quais nós legitimamos todas as outras práticas sociais, muitas das quais envolvem fluxos substanciais de matéria e energia. (LEMKE, 1993a, p. 16; tradução nossa)

Posicionar-se contra algumas minorias não é mais tolerado. E as redes sociais e mídias digitais (incluindo as versões digitais dos jornais impressos) moldam o comportamento do ser humano do século XXI. As constantes tensões de vozes "comuns" (representadas por pessoas "comuns" nas redes sociais) contra as vozes que, antes, detinham o direito de falar (representadas pelas vozes dos comunicadores tradicionais) estão causando essa mudança social. E nós estamos falando de dentro desse movimento de mudança. A audiência não é mais silenciosa, embora ainda seja regida, a nosso ver, pelos bens simbólicos, sempre em negociação, resultantes dessas interações.

\section{CONSIDERAÇÕES FINAIS}

A repercussão do fato ocorrido, no Programa Sílvio Santos, em relação à homossexualidade, bem como a omissão, das mesmas mídias que repercutiram o fato, em relação àqueles que não acreditam em Deus, demonstram que os dois temas são tratados de forma diferenciada na nossa cultura.

De acordo com o Censo do IBGE, no ano 2000, o número de pessoas que se declaravam "sem religião" era 12,5 milhões (7,3\%). Em 2010, ultrapassaram 15 milhões $(8,0 \%)$. Declarar-se dessa forma não significa ser descrente. Por outro lado, demonstra que os crentes podem estar perdendo a identificação com as religiões. No entanto, há, ainda, a predominância de uma espécie de repúdio aos descrentes, como pudemos verificar nos dados. Mais do que isso, há um silenciamento (ORLANDI, 2007) nos próprios dados, visto que o IBGE contabiliza o grupo dos descrentes junto a um grupo de crentes (os crentes sem religião), o que inviabiliza que tenhamos uma estatística correta em relação aos descrentes.

Ainda que a estrutura social sofra a interferência "forçada" por movimentos sociais de minorias, é possível percebermos resistências, na maioria das vezes, sob forma de silenciamento (ORLANDI, 2007). "Nós podemos e fazemos história, mas não como desejamos" (LEMKE, 1993a, p. 21; tradução nossa), devido à nossa inserção em uma dinâmica social que envolve supersistemas e subsistemas dependentes entre si, os quais são, tanto os organismos quanto os ecossistemas, constituídos pela ação e, ao mesmo tempo, são agentes integrantes e reguladores dos super ou subsistemas que eles contêm, gerando uma imprevisibilidade na evolução cultural. Cada indivíduo ou comunidade desenvolve, de sua própria maneira, novas práticas discursivas.

Nossa análise demonstrou que o silenciamento de determinadas formações discursivas, dentro da complexidade do discurso religioso, acontece sob a forma da política da palavra, mais especificamente, sob o apagamento estatístico de um grupo minoritário (como o exemplo do Censo do IBGE) e, em outros casos, quando esse grupo aparece "listado", sob a forma de um preconceito social, construído historicamente pelo poder da Igreja junto ao Estado (censura). Se, por um lado, há um repúdio em torno da 
discriminação de grupos minoritários, por outro, esse repúdio se mostra seletivo, ignorando outros tipos de discriminação menos alardeada pelas mídias e pelos ativistas que consomem conteúdos dessas mídias.

Temos que levar em consideração que, embora vivamos numa sociedade ainda muito afetada pelo poder histórico da Igreja Católica, esse poder se dispersou, com o passar do tempo, em diferentes formas de crer. Os católicos não são iguais; não pensam exatamente da mesma maneira, ainda que justifiquem seus diferentes pontos de vista como vindo dessa mesma fonte, que é a Igreja Católica. Além disso, o efeito da religiosidade originada da Igreja Católica é diferente também no Brasil do que é, por exemplo, em alguns países da Europa. O "fazer-em-uso da linguagem difere dependendo do registro e do sistema ecossocial no qual o processo contínuo de mudança da linguagem ocorre" (LEMKE, 1993a, p. 16; tradução nossa), produzindo, assim, essa inconsistência nos argumentos sobre tolerância.

Nosso empreendimento supõe, parece-me, levar a sério a noção de materialidade discursiva enquanto nível de existência sócio-histórica, que não é nem a língua, nem a literatura, nem mesmo as "mentalidades" de uma época, mas que remete às condições verbais de existência dos objetos (científicos, estéticos, ideológicos...) em uma conjuntura histórica dada. (Pêcheux, 2011, p. 151-152).

Se o sentido é, então, determinado pela conjuntura histórica, poderíamos sugerir que as opiniões analisadas, enquanto materialidades linguísticas dessa conjuntura, demonstram que, no imaginário popular majoritário, não ter fé ainda está relacionado a uma espécie de falha de conduta. E isso ocorre até mesmo em espaços de "formações discursivas tolerantes". O que queremos dizer com isso é que há uma incoerência, que nos levou a fazer essa análise da forma que fizemos. Dito de outra forma, sentimos a necessidade de fazer conversar o silenciamento como política da palavra com o teoria da dinâmica social. Por essa via de análise, concluímos que o "sujeito-tolerante" sofre uma fragmentação relacionada a discursos sobre diferentes temáticas a respeito de tolerância. Ele é atravessado pela materialidade histórica, que funciona diferente para cada temática. Por ser atravessado por formações discursivas diversas, ao mesmo tempo, mas em estágios diferentes de disputas de sentidos dentro desse recorte de tempo de vida, os sujeitos não são coesos em suas manifestações discursivas. A dinâmica dos discursos em disputa se mostra de forma latente na incoerência da materialidade discursiva sobre a tolerância (com valor positivo sobre um grupo minoritário e negativo sobre outro).

A inserção desse caminho teórico-metodológico que desenvolvemos não nos dá respostas sobre o porquê da ocorrência dessas incoerências - e nem deveriam -, mas pensamos ser importante para que se evidencie tais incoerências, das mídias e de seu público, para que se jogue luz sobre preconceitos silenciados sob a forma de valores simbólicos nas mídias.

\section{REFERÊNCIAS}

ALTHUSSER, Louis. Aparelhos ideológicos do Estado. $2^{\mathrm{a}}$. ed. Trad. de Valter José Evangelista e Maria Laura Viveiros de Castro. Rio de Janeiro: Graal, 1985. 
BOURDIEU, Pierre. Gênese e estrutura do campo religioso. Em: A economia das trocas simbólicas. São Paulo: Perspectiva, 2007.

CAPRA, Fritjof. A teia da vida: uma nova compreensão científica dos sistemas vivos. Trad. de Newton Roberval Eichemberg. São Paulo: Cultrix, 1996.

IBGE [Instituto Brasileiro de Geografia e Estatística]. Características gerais da população, religião e pessoas com deficiência. [on-line] Disponível em: biblioteca.ibge.gov.br/visualizacao/periodicos/94/cd 2010 religiao deficiencia.pdf. Acesso em 19/11/2016.

LEMKE, Jay L. Discourse, dynamics, and social change. Cultural Dynamics, 6(1), p. 243-275, $1993 \mathrm{a}$.

ORLANDI, E.P. As formas do silêncio: no movimento dos sentidos. $6^{\text {a }}$. ed. Campinas: Editora da Unicamp, 2007.

Análise de discurso: princípios e procedimentos. Campinas: Pontes, 1999.

. (Org.). Palavra, fé, poder. Campinas: Pontes, 1987.

PÊCHEUX, M. Especificidade de uma disciplina de interpretação (A Análise do Discurso na França). Em: PÊCHEUX, M. Análise de Discurso: Michel Pêcheux [Textos selecionados por Eni Puccinelli Orlandi]. 2a. ed. Campinas: Pontes, 2011. pp. 227-230.

Artigo recebido em: junho de 2017.

Aprovado e revisado em: dezembro de 2017.

Publicado em: maio de 2018.

\section{Para citar este texto:}

REZENDE, Clauton de. Uma análise da repercussão de discursos discriminatórios na mídia, sob a ótica da dinâmica social. Entremeios [Revista de Estudos do Discurso, ISSN 2179-3514, on-line, www.entremeios.inf.br], Seção Estudos, Programa de PósGraduação em Ciências da Linguagem (PPGCL), Universidade do Vale do Sapucaí (UNIVÁS), Pouso Alegre (MG), vol. 16, p. 3-21, jan. - jun. 2018.

DOI: http://dx.doi.org/10.20337/ISSN2179-3514revistaENTREMEIOSvol16pagina3a21 


\section{ANEXOS}

ANEXO I

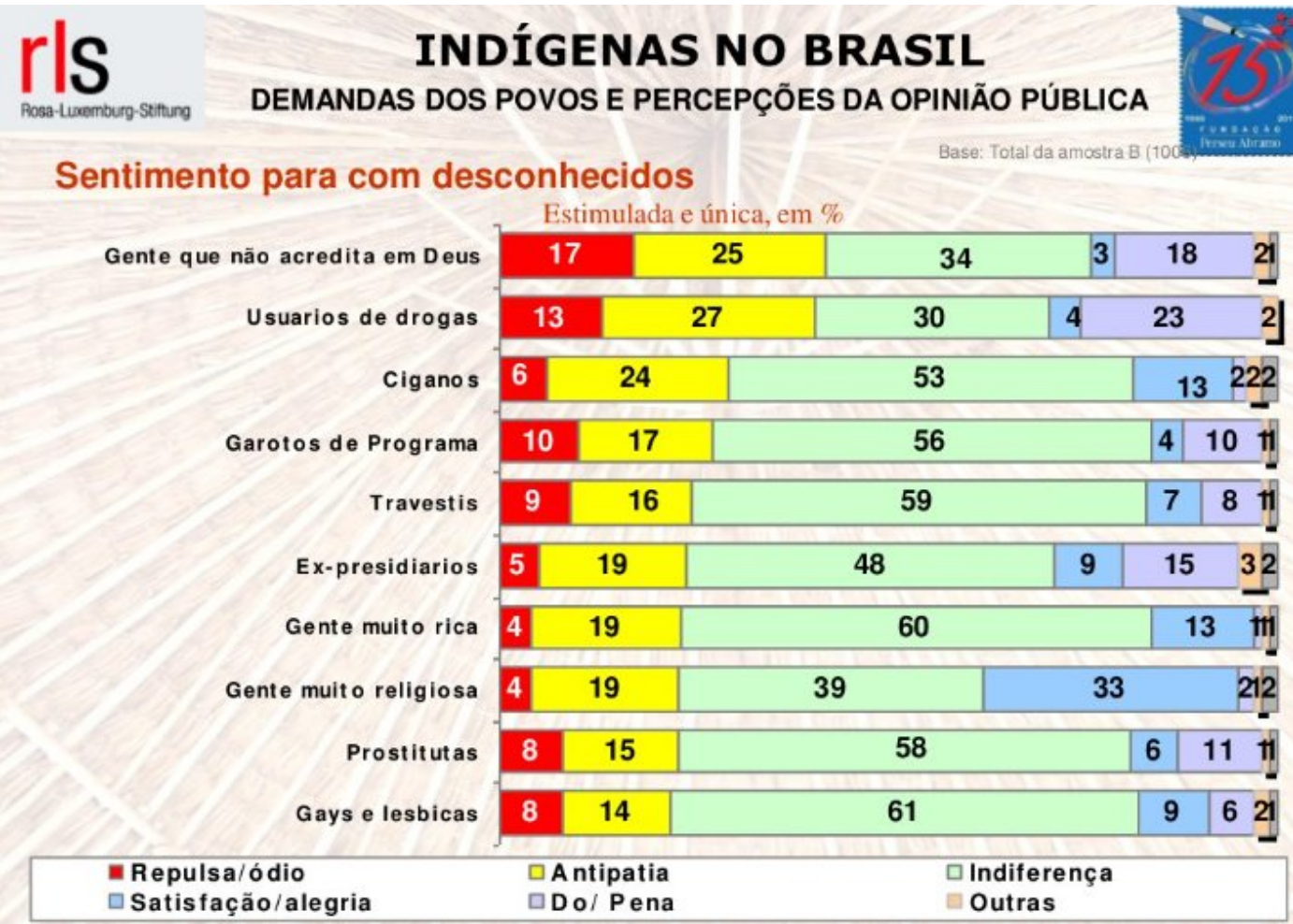

P5. Vou falar de alguns tipos de pessoas e gostaria que o/a sria. me dssesse o que o/a sr/a. sente normalmente quando vê ou encontra desconhecidos do tipo deles.

Figura 1. Ateus como a minoria que recebe o maior sentimento de Repulsalódio, de acordo com a FPA. 
ANEXO II

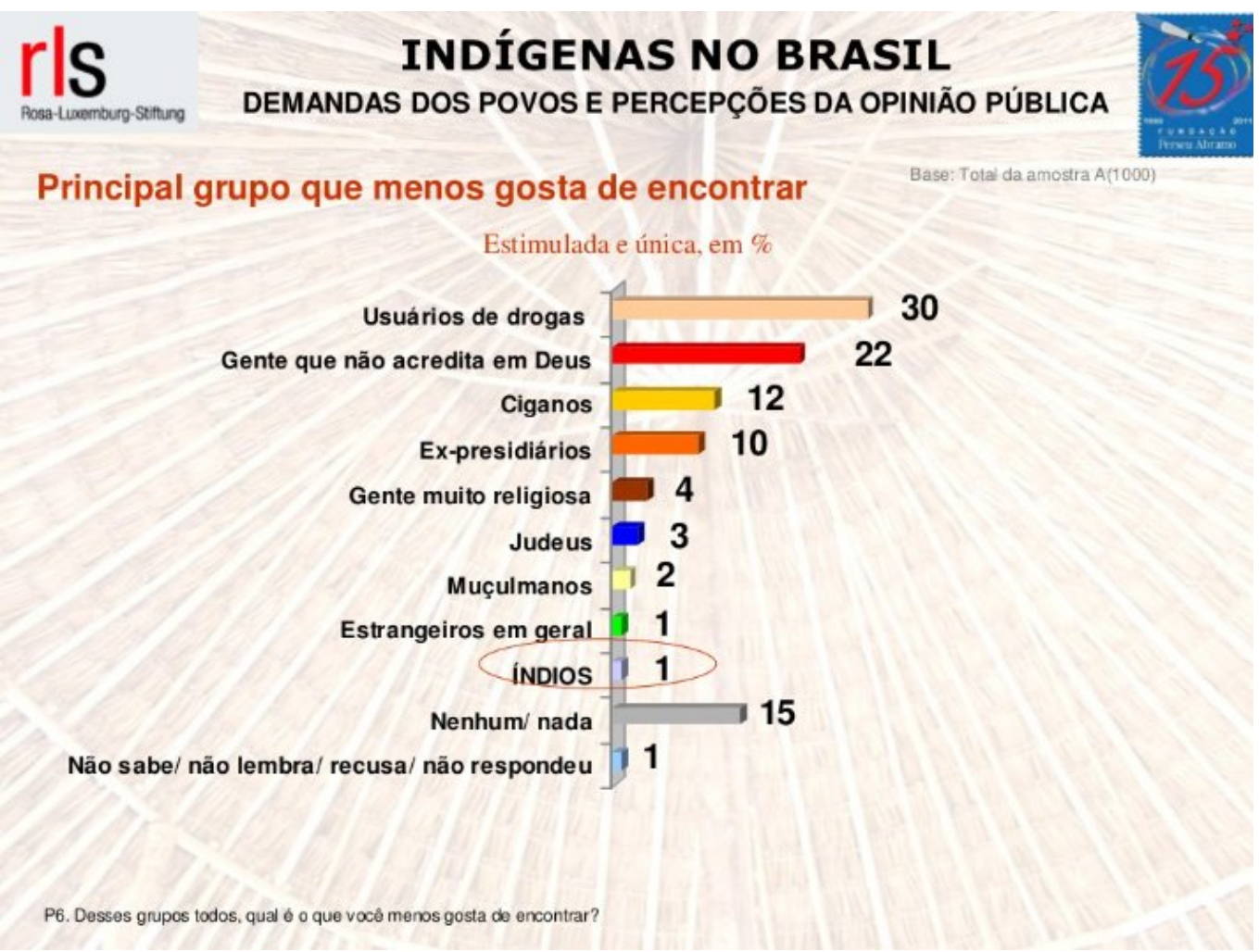

Figura 2. Ateus em segundo lugar relacionado à pergunta "Desses grupos, qual é o que você menos gosta de encontrar?"

ANEXO III

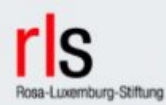

INDÍGENAS NO BRASIL

DEMANDAS DOS POVOS E PERCEPÇÕES DA OPINIÃO PÚBLICA

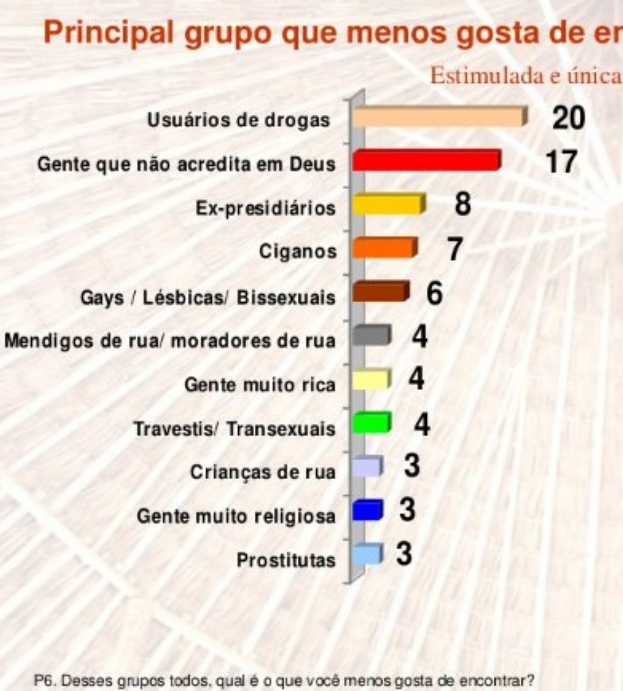

ncontrar
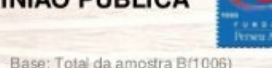

Figura 3. Ateus em segundo lugar relacionado à pergunta

"Desses grupos, qual é o que você menos gosta de encontrar?", com a inclusão de mais grupos. 
ANEXO IV

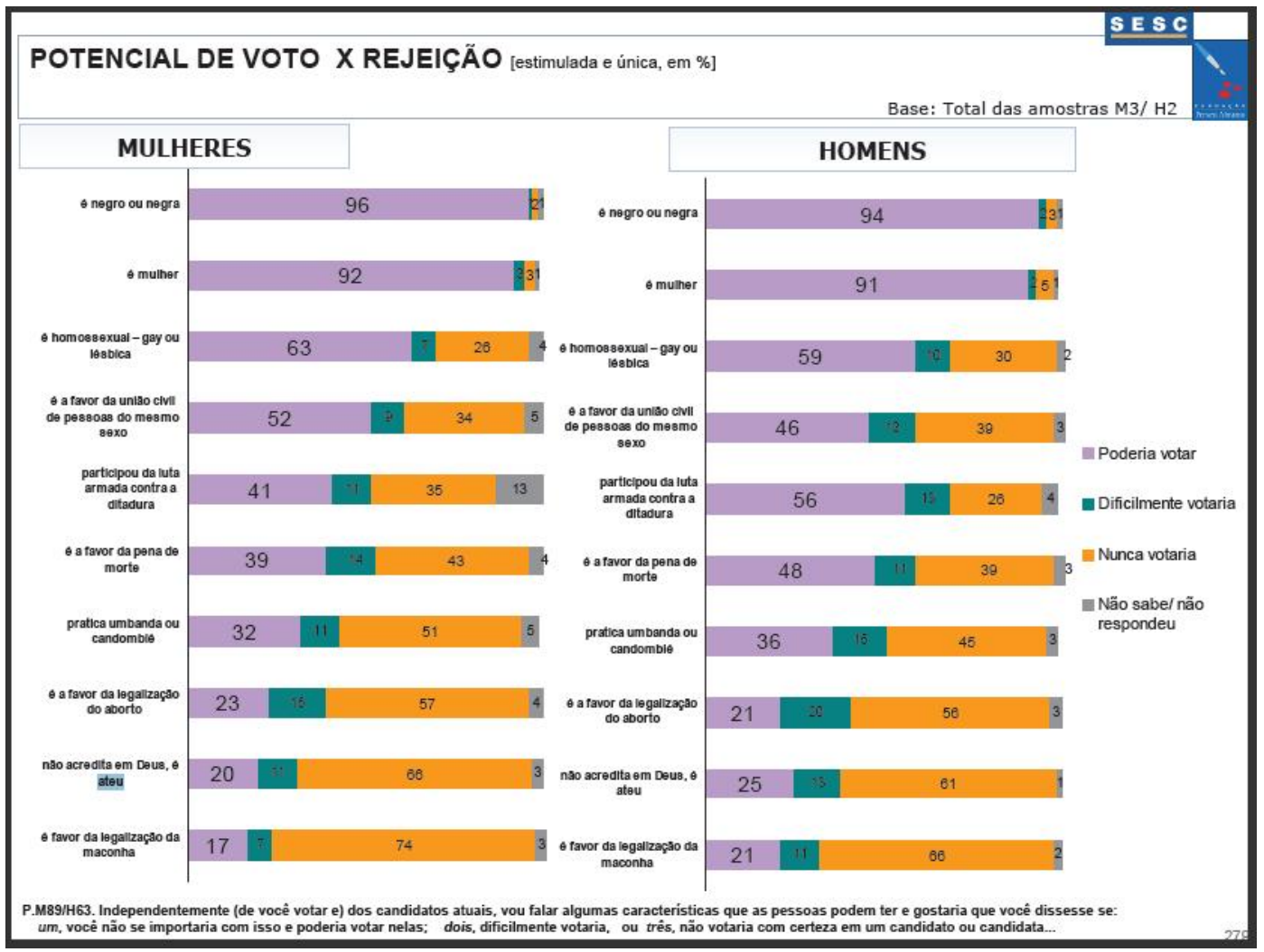

Figura 4. Ateus como o segundo grupo mais rejeitado, caso fossem representados por um candidato à presidência

ANEXO V

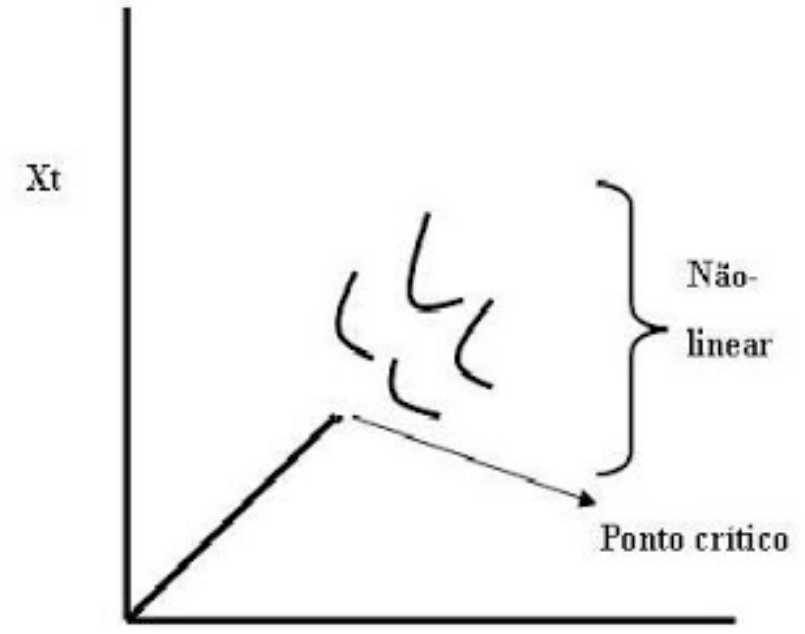

Figura 5. Representação gráfica de um "ponto de bifurcação". 